on several of their manuscripts! We finally settled on a combination of current or former associate editors or editors.

The specific question pertains to a frequently cited article in which we described experimental (functional analysis) approaches to the assessment of self-injurious behavior, which was not published in $J A B A$. I am often asked if the manuscript was rejected by $J A B A$ or, if not, why it wasn't submitted there. At the time, I was an associate editor, and the status of assessment studies was unclear. Because our manuscript contained no treatment data whatsoever, I predicted either a prompt rejection or a requirement to add treatment results for our 9 subjects, which I was afraid would detract from the main thrust of the study. We submitted the manuscript elsewhere. In retrospect, it was an error in judgment; I should have allowed the $J A B A$ shaping process to run its course.
Department of Psychology
The University of Florida
Gainesville, Florida 32611

Jon S. Bailey (Editor, 1987-1989)

\title{
LIVING AT THE CENTER OF THE UNIVERSE
}

It was the best of times. It was the worst of times. The worst came first.

George Ackley, my trusted editorial assistant (more on him later), and I were anxiously awaiting the truckload of material that comes with the office of editor of the Journal of Applied Behavior Analysis. We were expecting four ancient fourdrawer file cabinets containing all the reviews and editorial decisions for all the manuscripts being processed and a dozen or so boxes of office supplies, including the all-important instructions on "How to Run the Journal Office." We waited, and we paced like expectant fathers, and we waited some more, for days, long past the date the truck was to arrive from Baltimore. We were receiving new manuscripts in the mail, and authors were calling to request updates on the status of papers they had recently submitted. The trucking company insisted the load had been delivered, or was about to be delivered, any time now. We were told to "be patient, these things take time you know. We'll look into it for you." Tenure decisions were hanging in the balance, I learned from authors so stressed out that they audibly gasped when informed about our predicament. I wasn't really the editor yet, and I did not have any record of their manuscript; it would be in the files, I assured them. We were waiting, and we were pacing. We were in limbo.

The tradition is that the editor-to-be visits the office of the current editor sometime in the summer before the late August transition. I had duly, and happily, visited the immaculate and efficiently organized JABA office at the J.F.K. Institute at Johns Hopkins where Brian Iwata had set up shop some 3 years earlier. Although I served as a member of the editorial board for several years and had completed a four-year term as an associate editor, I had never actually seen the editorial office. I entered with awe as one would a shrine, which it is in a sense; the ancient file cabinets, passed down from one editor to another, with the proper blessings and sacred instructions modified only slightly through the years.

Mont Wolf and Todd Risley and Don Baer in 
their collective genius envisioned a review process that would shape the field (a "postdoctoral course in research methods" is the way Todd explained it) by allowing at least three experts to review each manuscript (the fourth reviewer was often a new researcher who had just recently submitted a paper to $J A B A$, which had probably been rejected). The author received unedited copies of the four reviewers' comments along with the associate editor's decision letter; each of the reviewers received copies of all the critiques as well. Although the process is called "blind review," reviewers quickly learned to be compulsive, critical, and attentive to detail; they leaned toward rejection even before reading a manuscript just so they would not be the only person to accept a paper that had been given thumbs down by their peers. As unlikely as it sounds, it worked, and the peer feedback along with an internal public posting system and regular round robin exchanges of complete packets for associate editors kept everyone on their toes. Authors held their breath waiting for a $J A B A$ decision, knowing the odds were against them (the not-so-secret $85 \%$ rejection rate added just a touch of excitement to the otherwise mundane chores of everyday scientific and professional behavior).

As soon as George and I could get our hands on the cargo, we could get down to business; we were, as I said, anxious about it. The trucking company now was saying definitely the goods had been delivered. Definitely. Perhaps we were not at the office the day the delivery arrived. Maybe it had been delivered to some other Jon Bailey (there are six of us-I am the only "Jon"- - in Tallahassee, including a psychiatrist, a police officer, and two who do not pay their bills on time but who have a lot of rowdy friends who call late at night).

Because I was not working on the actual journal, I had some time on my hands to think about more lofty matters, like journal policy and the new directions we might take in the next 3 years. I received a few complaints about the "narrow," "elitist" nature of the journal from colleagues in the past few months and was interested in infusing a little new blood. I had been concerned for some time that many of the phenomena and findings in be- havior analysis are not directly or systematically replicated and realized that our editorial policy might actually have something to do with this (i.e., we encourage "original" research, possibly at the expense of well-done replications). At the same time, my experience as an associate editor convinced me that reviewers consistently rejected articles of a very innovative nature simply because there were minor methodological problems. "If it's not perfect, don't publish it," I was told by one prominent member of the board. Finally, JEAB had published, for a number of years, outstanding book reviews that are well crafted, informative, and provide extraordinary insight into the topics covered. As I told Charlie Catania at a SEAB dinner at ABA, "I covet your $J E A B$ book reviews. How do you do it?"

I bounced these and a few other ideas off Mont Wolf and Brian Iwata and announced in my first editorial (Bailey, 1987b) that $J A B A$ would henceforth encourage authors to submit Replications and Innovations. I also announced that I would encourage readers to submit book reviews. To liven up the journal, I created Comments from $J A B A$ Readers, thinking that it might be interesting to have something akin to a letters to the editor column where readers of $J A B A$ could tell us about their reactions to certain studies. We had a reader from Greece (Paschalis, 1987) inform us, for example, that tokens originated with the Greeks in the fifth century B.C. as a measure to encourage citizens to attend the General Assembly meetings. My own meager offering involved an incident at a Tallahassee park involving "terrorist geese" and a behavioral analysis thereof (Bailey, 1987a).

We finally tracked down the driver of the truck that supposedly delivered our long-lost JABA office supplies and equipment. From a phone booth in Texas he described our building in detail and how it took him several trips and a lot of maneuvering to fit all of it into our closets. "What closets? We don't have any closets. All those file cabinets were to be delivered to my office, a big office, room 107 of the Psychology Building!" ' Talk to Theresa about it, she told me where to put it. Sorry pal, gotta go, I gotta get these eggs to El Paso," and he hung up. I raced up the stairs to the main office 
looking for the mysterious "Theresa," only to discover that just such a person had worked in the office for about 2 weeks but had been fired 2 days earlier for her inefficiency and ineptness. With a well-worn master key in my trembling hand, I quickly began opening closet doors in the long hallway just outside my office. Sure enough, behind the third door stood those beautiful, battered antique file cabinets. Two had been tipped over somewhere on the trip and the contents were in total disarray; one was so banged up it took a chisel to open it. George and I hugged each other and laughed, and I think I actually cried I was so relieved. One faculty member stuck his head out in the hall to ask if everything was all right. It was, I replied; I was now a real JABA editor, and I could get down to work.

When I first learned I was officially under consideration for the position, I knew who my first appointment would be. One of my graduate students, George Ackley, had prior editorial experience and in my opinion was one of the most careful and precise writers I ever met. He pored over his papers before he submitted them to me, and I could never catch him in a grammatical or typographical error. His mother was an English teacher and raised him right, or well, whatever. He was the most punctual, on-task, organized, and responsible person within 50 miles. George agreed to do the job, and for 3 years he was my most trusted editorial assistant, companion, and confidant. With his expert skills he managed to computerize much of the manuscript processing for $J A B A$, streamlined the review procedures, and brought new meaning to efficiency in office management.

With the day-to-day operation under control, I could focus on trying to influence the journal's direction. Actually the editor has much less control over this than one might imagine. In reality, the associate editors make the judgments about which manuscripts to accept, and of course they are strongly influenced by the reviewers' recommendations. In my meetings with them, I stressed the importance of looking for innovative manuscripts and giving them a chance, and I encouraged them to prompt researchers they saw giving interesting pa- pers or posters at conferences to submit them to $J A B A$. I let the associate editors know, however, that I would abide by their decisions. Overriding them, I knew, would be demoralizing. In my 3 years, I had only two problems regarding editorial decisions. In one case, I felt a paper should have been accepted with revisions because it was so creative and innovative; I knew it would be quickly published in another journal. I called the associate editor and discussed it at length; he disagreed. I called again a few days later and discovered that he had changed his mind. By the time I was able to track down the author, he had submitted the paper to another journal, and we lost a very interesting paper that was provocative and timely.

I use $J A B A$ in my teaching all the time. I assign journal articles for students to read in class, I present certain favorite articles, and when I teach Introduction to Applied Behavior Analysis I require that the students subscribe to the most current volume. It had always bothered me that the graphs in some terrific studies were poorly prepared and often found myself actually redrawing them so that they could be presented in class. At last as the editor I would be able to assure that the graphs were properly drawn before they were finally published. I was surprised to realize how difficult this was and how resistant authors were to the notion that just as their manuscript would have to be revised before publication, so would the graphs. One person told me about the hundreds of dollars she spent having her figures professionally prepared and how she wasn't about to pay out the money again. Another person informed me that he would withdraw the paper rather than go through the pain and agony of redrawing his figures. George and I educated many authors about the ease of preparing graphs using MacDraw ${ }^{\circledR}$ software and a user-friendly Macintosh ${ }^{\circledR}$ computer. Another one of my students, Dave Pyles, cleaned up many a graph for authors.

There are many disappointments associated with serving as editor. One of my major ones was my inability to follow through on an initiative that I called "Progress in the Experimental Analysis of Behavior" (Bailey, 1987b), in which I hoped to assure that as applied behavior analysts we kept 
in touch with our basic research roots. Nancy Neef, bless her heart, thought it was a good idea but so greatly improved on the concept that I can take no credit. The publication of " $J E A B$, November '92: What's in it for the $J A B A$ reader?" (Hineline \& Wacker, 1993) and the associated abstracts of key articles from $J A B A$ is an innovative and scholarly effort if I ever saw one. I urge $J A B A$ readers to make good use of this resource in training their graduate students of the next generation and in guiding their research.

My second disappointment involved my inability to produce book reviews on a regular basis. I did not have the time, nor the skill, to do them myself, and the several people I asked to do them were not able to accomplish this task in a reliable fashion either. I believe it is still a worthy project and hope that some future editor can find a way to give more exposure to all of the new books that come out on behavior analysis.

As I came to the end of my term, I began to realize that the editor sits at the center of the universe of this field. We see the manuscripts before anyone else and are as close in time to the latest findings and controversies in our field as anyone gets. The built-in time lags in publication mean that from the time an article is logged in at $J A B A$ until it appears in your mailbox might be a full year. I found this proximity to the latest innovations in the field to be perhaps my greatest reinforcer, along with the opportunity to interact with authors to help shape their sometimes rough manuscripts into exciting published papers, with perfect graphs.

I worked with some fantastic colleagues. Kathy Hill is an extraordinarily gifted managing editor, and Mary Lou Wright is our perennial business manager for all seasons. She was willing to consider almost any crazy idea for promoting the journal and provided a solid shoulder to cry on in the toughest of times. I would also like to thank the associate editors I worked with over a 3-year period for their exceptional devotion to the field and their tireless efforts to produce the highest quality journal possible: Wayne Fuqua, Brandon Greene, John
Martin, Nancy Neef, Ron Van Houten, John Parrish, Susan Fowler, David Wacker, and Andy Egel.

Mont Wolf was my inspiration throughout it all. As the first editor, he set the tone and gave us all a model to follow. I cannot thank him enough for the high-quality training he gave me as my major professor at the University of Kansas. Finally, I would like to thank Brian Iwata for turning the journal over to George and me in such superb condition. Once we found it, right under our noses across the hall, we were amazed at how clearly everything was laid out. I continued to rely on Brian for his expert advice and counsel during my entire tenure.

As my time came to an end and as the formal survey of former editors, associate editors, and editorial board members indicated that Scott Geller was the overwhelming choice for the next editor, Brian and I plotted a strategy to break it to him. We chose a conference we would all be attending in St. Petersburg, and, despite the fact that Scott was already overcommitted, he agreed to sign on.

Scott wisely sent his assistant to pick up the $J A B A$ office files in a rental truck; this time, they were safely delivered to their new home. Scott called me to announce the arrival of $J A B A$, as one would proudly announce the birth of a baby. I thanked him and wished him the best. The torch was passed; we had a new editor.

\section{Psychology Department}

Florida State University

Tallabassee, Florida 32306

\section{REFERENCES}

Bailey, J. S. (1987a). Behavior analysis in action. Journal of Applied Bebavior Analysis, 20, 427.

Bailey, J.S. (1987b). The editor's page. Journal of Applied Bebavior Analysis, 20, 3-6.

Hineline, P. N., \& Wacker, D. P. (1993). JEAB, November '92: What's in it for the JABA reader? Journal of Applied Behavior Analysis, 26, 269-274.

Paschalis, A. P. (1987). Tokens and their economy: The Greeks had a use for them. Journal of Applied Behavior Analysis, 20, 427. 